\title{
Analysis and Multi-objective Optimization on the Stamping of High Strength Steel
}

\author{
Wenyu Ma*, Jianwei Yang, Jun Zhang, Ye Yao, Shaobo Li and Xuebin Zheng \\ Research Institute of Technology of Shougang Group Co., Ltd., China \\ Beijing Key Laboratory of Green Recycling Process for Iron \& Steel Production Technology, China \\ Beijing Engineering Research Center of Energy Steel, China \\ ${ }^{*}$ Corresponding author
}

\begin{abstract}
In recent years, the high strength steel has gained great attention. And springback is an obvious drawback. In this study, the analysis was conducted on the relationship between thinning, springback and blank holder force, friction coefficient. The central composite design of tests and finite element simulation were used.The response surface method was employed.The maximum thinning increases with the increase of blank holder force and friction coefficient. The maximum springback value decreases with the increase of blank holder force and friction coefficient. And the multi-objective optimization was employed to optimize the thinning and springback. And the maximum thinning increases with the decrease of maximum springback value.
\end{abstract}

Keywords—high strength steel; springback; thinning rate; optimization

\section{INTRODUCTION}

In recent years, lightweight in automotives is a trend in order to protect the environment and reduce the consumption of fossil fuel [1]. So the lightweight material was widely used, such as aluminum alloy and high strength steel. Many components in the automotive were made of high strength steel to decrease the weight and maintain a high strength meeting the requirement. Much effort was highly paid to the development of high strength steel in the last years. F Ajersch et al. [2] reviewed the galvanizing operations of steel to decrease the surface defects and discussed the formability and application of high strength steel in automotive manufacturing area. Some kinds of high strength steel were mentioned and discussed in the study. Hao et al. [3] conducted the experiments to test the formability of TWIP and TRIP steels. The forming limit diagram was built after the test and the material model was established. High strength steel parts are generally stamped at the room temperature. Much effort has been devoted to this research area [4].Cold stamp operation is simply manipulated compared with other forming method, for example superplastic forming, hot stamping and hydraulic forming. Some components can be formed in one stamping operation followed by punching, flanging and other procedures. The careful tool steel selection for the cold forming of the high-strength steels employed is conducted based on the stress distribution in tools. G. Ingarao et al. [5] studied the formability of an S-shape channel part using the finite element (FE) analysis. The material used in this study is dual phase steel. The thinning reduction and springback reduction were considered in the stamping operation. Ma et al. [6] analyzed the springback and thinness of a panel component used in the automotive in the hot stamping process. FE model and optimization method were employed in this study. In this study, the study on the cold forming of high strength steel was conducted. The analyzed project is the relationship between the forming index, namely the minimum thickness and the springback, and the forming factors, namely blank holder force and friction coefficient. The response surface was employed to draw the result. Finally, the conclusion was obtained. The multi-objective optimization was also employed.

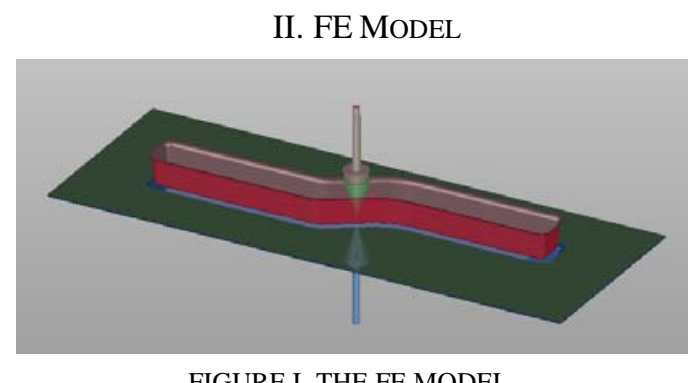

FIGURE I. THE FE MODEL

The FE model has four parts, namely die, blank, punch and blank holder. The die, punch and blank holder were set as rigid body. The blank is about $480 \mathrm{~mm}$ length and $190 \mathrm{~mm}$ width. The material is DP590 produced by Shougang Group. The Young's Modulus is 2.1e5 MPa, the Poisson' Ratio is 0.3, rm is $0.925, \mathrm{n}$ is $0.16, \sigma_{0}$ is $375 \mathrm{MPa}$.

\section{THE TEST DESIGN}

There are two design factors selected, namely the friction coefficient and the blank holder force. The tests were designed using an efficient design method, which is Central Composite Design. With the help of this design, a minimum of nine tests can be used to analyze the relationship between the response value and design factors. One of the responses is the minimum thickness value and the other is the springback value. The minimum thickness can also be replaced by the maximum thinning rate. Table 1 is the test factors, namely blank holder force and friction coefficient. Table 2 is the specific factor value and the corresponding results. 
TABLE I. THE TEST FACTORS AND THEIR LEVELS.

\begin{tabular}{lllllll}
\hline & & Low & High & -alpha & +alpha & Mid \\
\hline A & BHF & 1000 & 1400 & 917.2 & 1482.8 & 1200 \\
B & $\mathrm{u}$ & 0.05 & 0.13 & 0.033 & 0.147 & 0.09 \\
\hline
\end{tabular}

TABLE II. THE DESIGN OF TESTS AND THE CORRESPONDING RESULTS.

\begin{tabular}{lllcr}
\hline No. & BHF & $\begin{array}{l}\text { Friction } \\
\text { coefficient }\end{array}$ & $\begin{array}{l}\text { Max } \\
\text { thinning }\end{array}$ & springback \\
\hline 1 & 917.16 & 0.09 & 0.211 & 1.777 \\
2 & 1000 & 0.05 & 0.205 & 1.97 \\
3 & 1000 & 0.13 & 0.242 & 1.528 \\
4 & 1200 & 0.09 & 0.225 & 1.695 \\
5 & 1200 & 0.15 & 0.27 & 1.299 \\
6 & 1200 & 0.03 & 0.212 & 2.174 \\
7 & 1400 & 0.05 & 0.216 & 1.964 \\
8 & 1400 & 0.13 & 0.262 & 1.386 \\
9 & 1482.84 & 0.09 & 0.228 & 1.654 \\
\hline
\end{tabular}

\section{RESUlTS AND DISCUSSION}

According to the test results, the response surface method is employed to analyze the relationship between thinning, springback and friction coefficient, blank holder force. The fitting equation is as follows, where, $f(1)$ is thinning, $x(1)$ is blank holder force and $\mathrm{x}(2)$ is friction coefficient.

$f(1)=0.11945+1.59089 e-4 * x(1)-0.74992 * x(2)+2.8125 e-4 * x(1)$ $* x(2)-6.25 e-8 * x(1)^{\wedge} 2+5.15625 * x(2)^{\wedge} 2$

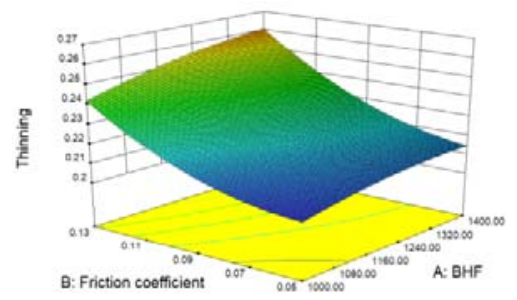

FIGURE II. RESPONSE SURFACE OF THE THINNING FOR DP STEEL.

The thinning increases with the increase of blank holder force and the increase of friction coefficient. Because when the blank holder force increases, it is hard to draw the blank into the hole and the large friction coefficient also constrain the movement of the blank.

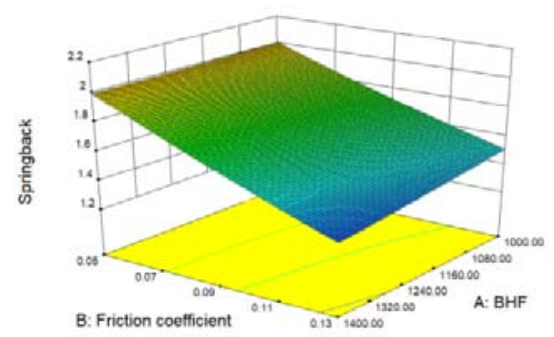

FIGURE III. RESPONSE SURFACE OF THE SPRINGBACK FOR DP STEEL.

At the same time, the large blank holder force and friction coefficient leads to a low springback value. Because, the large blank holder force and friction coefficient would change the distribution of the stress in the blank. The fitting equation for springback is as follows, where, $\mathrm{f}(2)$ is springback.

$f(2)=2.44269-2.23718 e-4 * x(1)-3.89512 * x(2)-4.25 e-3 * x(1) * x(2$ )$+1.6875 e-7 * x(1)^{\wedge} 2+10.78125 * x(2)^{\wedge} 2$

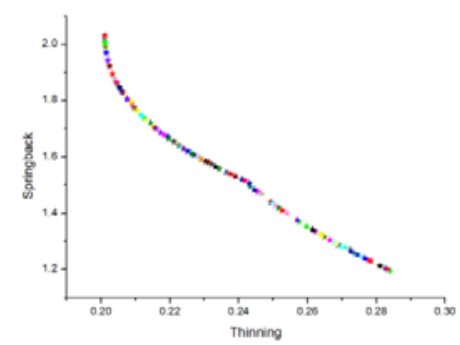

FIGURE IV. THE PARETO FRONTIER FOR THE THINNING AND SPRINGBACK.

In order to get a further understanding on the relationship between springback and thinning, the optimization program was employed. As is shown in Figure 4, the maximum springback value increases with the decrease of the maximum thinning rate value in the Pareto frontier. So these two indexes are contrary.

The model-predicted results and simulated results in terms of the selected points from the Pareto Frontier were shown in the following table.

TABLE III. THE COMPARISON BETWEEN THE MODEL-PREDICTED AND SIMULATED VALUE.

\begin{tabular}{lllrllllc}
\hline Points & BHF(kN) & \multicolumn{1}{c}{ u } & Predicted & \multicolumn{3}{c}{ Simulated } & Deviation \\
\hline & & & thinning & springback & thinning & Springback & thinning & Springback \\
1 & 917 & 0.0538 & $20.1231 \%$ & 1.992 & $20.5 \%$ & 2.069 & $-1.84 \%$ & $-3.72 \%$ \\
2 & 964 & 0.134 & $24.3135 \%$ & 1.507 & $24.2 \%$ & 1.535 & $0.47 \%$ & $-1.82 \%$ \\
3 & 1483 & 0.133 & $26.4895 \%$ & 1.3162 & $26.9 \%$ & 1.245 & $-1.53 \%$ & $5.72 \%$
\end{tabular}

Three points were selected from the Pareto Frontier. The model-predicted results were compared with the simulated results. From the Pareto frontier, the blank holder force and friction coefficient for these three points can be got according to the optimization result. At the same time, the corresponding process parameters' values were also got and used for FE simulation analysis. The simulated results were given in the table. The deviation values between predicted and simulated results were calculated and the deviation is indistinctive, which shows a good correspondence.The comparison of model-predicted results with simulated results shows a good prediction ability of the model.

To guide the factory manufacturing, the range of BHF and friction coefficient can be arranged according to the requirement of thinning rate and springback. The Following table is built according to the Pareto Frontier. In this table, the 
thinning rate is about $22 \%$ and the springback value is about $1.6 \mathrm{~mm}$. The blank holder force is from 917 to 940 and the friction coefficient is from 0.11 to 0.12 .

\begin{tabular}{rrrr}
\multicolumn{4}{c}{ TABLE IV. THE SELECTED OPTIMIZED DESIGN VALUES AND } \\
RESULTS. \\
\hline BHF(kN) & Friction coefficient & Thinning rate & Springback/mm \\
\hline 928.245 & 0.110079 & 0.221939 & 1.64803 \\
917 & 0.112213 & 0.222495 & 1.64079 \\
917 & 0.112637 & 0.222778 & 1.638513 \\
917 & 0.114316 & 0.223917 & 1.629538 \\
917.8933 & 0.116023 & 0.225173 & 1.620112 \\
917 & 0.117746 & 0.226333 & 1.611395 \\
918.1523 & 0.118404 & 0.2269 & 1.607461 \\
939.8218 & 0.118105 & 0.228333 & 1.600101 \\
917 & 0.121301 & 0.228966 & 1.592854
\end{tabular}

The combination of design of experiment (DOE), FE simulation, response surface analysis and optimization program can obtain the optimized process parameter's value to meet the requirement of manufacturer.

\section{CONCLUSION}

In this study, an S-shaped part of U-channel stamping operation was analyzed in terms of high strength steel produced by Shougang Group. The central composite design of tests was used. And the optimization program was used to get the relationship between thinning and springback.

The maximum thinning increases with the increase of blank holder force and friction coefficient. The maximum springback value decreases with the increase of blank holder force and friction coefficient. In the pareto frontier, the maximum thinning increases with the decrease of maximum springback value. So the compromised value can be chosen for maximum thinning value and maximum springback value.

\section{REFERENCES}

[1] Wen-yu MA, B.W.L.F., Effect of friction coefficient in deep drawing of AA6111 sheet at elevated temperatures. Trans. Nonferrous Met. Soc. China, 2015. 25: p. 2342-2351.

[2] Christian Lesch, N.K.A.F., Advanced High Strength Steels (AHSS) for Automotive Applications Tailored Properties by Smart Microstructural Adjustments. Steel Research International, 2017. 87.

[3] DING Hao, D.H., et al., Formability of TRIP/TWIP Steel Containing Manganese of $18.8 \%$. JOURNAL OF IRON AND STEEL RESEARCH, INTERNATIONAL, 2011. 18(1).

[4] Hernández, R.R.M.D., Tool steel selection for cold forming of high strength steels based On the stress distribution in tools. Greyden Press,., 2007: p. 16-20.

[5] G. Ingarao, R.D.L.F., Analysis of stamping performances of dual phase steels: A multi-objective approach to reduce springback and thinning failure. Materials and Design, 2009. 30: p. 4421-4433.

[6] Wenyu Ma, B.W.J.Z., Multi-objective optimization of hot stamping of aluminum alloy blank. Journal of Harbin Engineering University, 2015. 36: p. 1-6. 